\title{
What do social work students think social work research is?
}

\author{
Anita Gibbs
}

Anita Gibbs moved to Dunedin in 1999 from the UK where she had been a probation officer. Since then she has researched, taught and published extensively in areas as varying as home detention, social work research methods, community treatment orders and more recently intercountry adoption.

\begin{abstract}
In New Zealand, social work students often undertake social work research training as part of their first qualification in social work. The focus of this article is to consider what social work students think social work research is and whether they think social work research should be part of normal, everyday practice or not. Forty-three social work students from Otago University participated in a small research project during 2009 aimed at exploring their constructions of social work research. They emphasised that social work research should be compatible with social work values like empowerment and social justice, and bring about positive change of benefit of service users.
\end{abstract}

\section{Introduction}

There has been much controversy and debate in the literature concerning definitions and constructions of social work research (Beddoe, 2010; Fook, 2009; author, 2005; Shaw, BriarLawson, Orme and Ruckdeschel, 2010). Should social work research be perceived of as unique, or like any other kind of generic social science research? (Carpenter, 2000; Shaw, 2007; Smith, 2009). McDermott (1996) understood social work research to be about intervention, use of the ecological model and focused on the poor and vulnerable. Dominelli (2005) also argued that social work research focuses on marginalised groups, and engagement with practice to transform it. Gibbs (2005) argued that social work research could encompass the study of any area of social work broadly defined, but that it should not be left to academics to undertake, rather that practitioners and service users could undertake social work research.

Others have identified important unique aspects of social work research: for example, Witkin (2000) has long been an advocate of social work research as empowerment, Humphries (2008) as social justice, Martinez-Brawley (2001) argued for inclusionary practices, and Beresford and Croft (2001) proposed service-user involvement.

Nevertheless, a considerable number of scholars argue for a broader, innovative, interdisciplinary view of social work research focused more on its quality, functions and purposes without the need for a specific social work only epistemology (Shaw \& Norton, 2008; Shaw et al., 2010; Phillips \& Shaw, 2011). Carpenter (2000) has advocated for its similarity 
to other disciplines and McLaughlin (2007) for its use as just one tool among many in the social worker's toolbox. Many view social work research as not unique but underpinned by eclecticism and pragmatism (Carpenter, 2000; Powell \& Ramos, 2010). So, while some would argue we need to avoid particular 'attachments' to specific methodologies (Shaw, 2007), others would argue that researchers cannot be value-free, and that they bring their own standpoints and political perspectives to social work research, and these will inevitably influence the kinds of social work research undertaken (Dominelli, 2005; Pease, 2010).

But what about practitioners and social work students? What might their understandings of social work research be? In a recent study in New Zealand, Beddoe explored social work practitioner views of research (Beddoe, 2010). She interviewed social workers via focus groups and individual interviews, and as part of a discussion about continuing professional development, she asked them about research. Most of the practitioners placed value on social work research to promote improved practice, as well as to justify or provide evidence to support practice. Practitioners also felt that there were going to be organisational constraints preventing significant research initiatives in the workplace. This meant that they tended to have low confidence in their own capacity to undertake research.

The lack of confidence to do social work research however defined is a consistent theme identified in the literature and the need to grow capacity and increase confidence through robust training courses and post-qualification support has increasingly been advocated for (Fouché \& Lunt, 2010; Gibbs, 2010; Orme \& Powell, 2007). Shaw and Lunt (2011) argue that ongoing support is essential, not just one-off research training courses.

Nash (2010) completed a review of MSW (masters in social work) research reports from social work students at Massey University. She highlighted how social work students feel a need to research topics of relevance to their own life experiences, for example many of her students chose to research the experiences of being a refugee or migrating to New Zealand because they themselves had arrived in New Zealand as refugees or migrants. Nash also explored how New Zealand social work students locate themselves as insiders to social work research, and that those who undertake social work research operate as reflexive social work researchers. For social work students at Massey University, issues of social justice and empowerment were critical, and the study from Otago, which is reported in the following paragraphs, also reflected similar concerns about values in research, but much more.

\section{The Otago research study}

In New Zealand, most undergraduate and postgraduate social work courses offer social work research training, and at Otago University specific training in social work research methods has been available since 2005. The research study undertaken for this paper involved the cohort of 2009 students undertaking a one-semester course 'Social Work Research: SOWK 321' (Gibbs, 2010). The aim of the course is to help social work students gain critiquing skills in social work research, and develop the skills necessary to undertake research within a bicultural framework in the full range of social work contexts that students will participate in during and after qualification. They first have to know what research is and gain skills of critiquing and understanding research. The course which has been detailed elsewhere (Gibbs, 2010) involved lectures and tutorials on epistemology, research processes and ethics, methods, skills, analysis, literature reviewing and report writing. 
In the 2009 cohort there were 43 students (36 women and seven men) taking this course; 18 students were completing the distance version of the course and 25 were completing this course on-campus. The two groups received the same content and undertook similar assignments but were slightly different in terms of their ages (distance students' average age was 38 years and on-campus was 28 years). Distance students were also more likely to have had many more years' experience of social care work prior to undertaking their formal social work training.

As part of their course students were asked to answer the following two questions: What is social work research? and What kind of social work researcher might I be? In addition, distance students were asked to reflect about social work research in the form of Blackboard discussion activities as part of on-line learning. The on-campus students did the same during their on-campus tutorials, but these comments were not recorded. The course as a whole had ethical approval from the University of $\mathrm{Otago}^{1}$ but I asked each student if they would be willing for myself and a tutor to analyse their introductory session comments answering the two questions, and their essay material also answering the same two questions, for this research project. Forty-two of the 43 students agreed to participate, with one student asking for their essay not to be analysed. The Blackboard comments around the theme of 'Should social work research be part of everyday practice or not?' were already available to the author on-line and were easily anonymised. None of the students objected to any of their material being used when I sent back drafts of the analysis. I also sent them a draft article to give them the chance to add further material or additional comment, or delete material they did not wish to have published. The detailed analysis occurred after the students had completed the course as care was taken to avoid students feeling that the research was linked in any way to their overall essay marks. The material was analysed using Thomas' general inductive approach (2006). Each essay was read and re-read to identify themes and then coded deductively and inductively alongside the two main research questions.

The limits of this research are that it gives only a snapshot of a particular group of students undertaking this specific course, at this particular time. Students may have been limited in their ability to answer the questions by their lack of experience of social work research, although 23 of the 43 did say they had had previous social work practice experience. It is also possible the students may have presented what they thought might be the right answers' in their essays and on-line commentary, in spite of being encouraged to undertake their own reflections and critiquing as to what they felt were the important aspects of social work research. Students were encouraged to do their own literature searching on the questions asked. To overcome the potential influence of the course teachers upon the students' reflections we did not teach directly to the questions, other than in the introductory sessions where we mentioned a few useful references and debated with students about definitions of social work research for about 30 minutes. The research was conducted after the course had finished so some distancing could occur between course lecturers and students, yet at the same time after the course had finished participating students were emailed drafts of the findings to allow them to amend or comment upon, or agree with. In a small qualitative study of this nature there will always be many potential influences upon the research, but

When the course was first introduced the staff co-ordinators gained ethical approval from the University of Otago research ethics committee to allow coursework-related small-scale research to be undertaken by staff and students. 
this does not reduce the necessity for the voice of student social workers to be heard on the topic of social work research. We now turn to the main themes highlighted by the students in this study.

\section{Findings}

\section{The special nature of social work research}

At the outset of their course students were to some extent not knowledgeable about social work research although they did understand key components of undertaking research such as doing literature reviews, devising questions and employing a range of data-gathering techniques. As they read more about social work research and gathered information for their written assignments they expressed more commitment to a view of social work research being compatible with traditional social work values and practices. As one student put it:

Social work research incorporates many different components, theories and practice approaches, all of which aim to be sympathetic towards the work and uphold core social work values.

Values mentioned included: addressing inequality, ensuring social justice and empowerment of participants and service users. Also, ideas about caring, enabling wellbeing, being holistic, being transparent, being accountable, ensuring human rights, and participation were regularly noted. Ethical issues like respect, do no harm, do not exploit, and maintain confidentiality were also considered important aspects of doing social work research. Having an ecological view and taking into account a range of practice and cultural contexts was viewed as important by a few students. Applying social work research to bring about positive change for service users was viewed as a very important component of social work research.

Hence for one student social work research was about:

People and their environment, and is a journey into the exploration and explanation of knowledge and practice bases of social work ... [and has] a strong commitment to social justice, reciprocity, empowerment and self-determination.

\section{The focus of social work research}

Three students commented that the focus of social work research ought to be: 'Find out what works and what doesn' $t$ ', 'researching the effectiveness of services', and 'without evidence based practice the practice of social work would be performed blindly or on trust of our own opinions'. These students were committed to the notion that social work research ought to produce evidence of effectiveness and that researchers should actively focus on gathering data which demonstrated whether or not particular social work practices worked. Other students agreed and felt that the aims of social work research should be to improve social work services, as well as provide the best possible service to clients by being prepared to do research which would explore social problems within the overall aim of bringing about social change. Students listed problems of crime, poverty, domestic violence, HIV / Aids and mental health as areas suited to social work research. One student summarised the overall view succinctly:

The focus of research is to provide accurate and valid data, which can be utilised to promote positive change for those suffering from oppression and marginalisation. 


\section{Methods and tasks}

Students felt that social work research would incorporate many of the aspects of traditional research practice. Hence, they made comments about the need to develop initial research questions, undertake literature reviews, collect data using a range of methods, complete analysis and reporting tasks. They were keen however to emphasise the importance of using reflective methods and being willing to work collaboratively with service users and different cultural groups to ensure accountability and ownership of research. As one student said:

Social work research is a process that can involve, and be initiated by the service users [and] social work researchers have a responsibility to care about those who are involved and participating in the research.

Students talked of using any method appropriate to answer research questions, which they felt was a more useful starting point for social work research than stating a preference for a particular method. So, although they were keen on applied collaborative-based research to improve practice and address social problems, they felt this could be achieved by using most methods in a pragmatic way. They talked of social work research as a tool to use when appropriate, and they mentioned qualitative and quantitative approaches equally. The Māori and Pacific Island students were more likely to favour indigenous research methods; these emphasised collaboration and community / service user involvement and were more likely to use face-to-face and group-based data collection techniques. The indigenous approaches would also emphasise 'protocols, beliefs, values and customs' of the group being studied.

\section{The kind of social work researcher I might be?}

At the outset of their course, social work students had few thoughts about the kind of social work researcher that they might become, even though some of them had previously participated as either researchers or participants in various social work research endeavours. Once students had given some serious time to reflect on this question they felt that there were certain features that were crucial to the kind of social work researcher they might be. Most of the students noted how their own background and beliefs would influence their social work research activity, and that as social work practitioners, the values of 'empowerment', 'self-determination' and 'self-awareness' would underpin this research activity. They felt it would be important to be 'reflective' and 'caring'. For some students, the perception of whether they would be insiders or outsiders made a difference to the kind of researcher they might become. Two comments highlight the insider/outsider influences on research:

As a researcher I would have to be consciously aware that I am an outsider, a non-expert and that it is the respondents who hold the knowledge.

As a Māori, the opportunity I have as an insider to the research will hopefully allow an insight that conveys the meaning and essence of the data collected.

When students thought about their own research practice compared to the general abstract idea of others doing research they expressed a preference for qualitative social work research, incorporating the use of interviews, action research, practitioner research, case studies and also mixed methods. One student noted: 'I would much prefer to work from a qualitative perspective where small numbers of texts, recordings and documentation would be analysed for different purposes'. Nevertheless, other students did mention that as researchers they valued quantitative data and would seek out such data to balance their qualitative research practice. 


\section{Social work research does need to be done on an everyday basis}

Distance students $(n=18)$, who were asked to consider if social work research ought to be integrated into their everyday practice, overwhelmingly felt that it should be, but they recognised significant factors that would prevent large-scale social work research being undertaken. One student summed up the tensions in the following way:

There are a few reasons why social work research should be a normal everyday activity. Firstly, it would increase knowledge, and secondly, create opportunities for reflexive practice to develop, thirdly, dependent on the research strategy it may also emancipate and empower service users. Conversely, it may overload a practitioner. How is it meant to fit in amongst all the other tasks required from the practitioner? Who is going to fund this?

Social work students identified two kinds of research that could be undertaken within social work. One was small-scale, informal, everyday research undertaken by practitioners. This could include monitoring, information gathered during assessment, feedback from consumers on programme benefits and reflective evaluation during supervision. Secondly, students felt there should be larger-scale specialised research undertaken by professional researchers (academic or well qualified academically). Small-scale research was viewed as achievable by the students imagining their role as practitioners, especially applied to improvement of practice.

\section{Discussion and implications for education and practice}

Student social workers believed in collaborative, practice-oriented and social problem solution-based social work research, within a strong values-based framework aimed at improving social work practice and client outcomes. At the same time, they noted that there were impediments to doing social work research like financial, time and organisational barriers. Sadly, these perceptions of impediments noted by Otago social work students are experienced in reality by other social workers in practice (Fouché \& Lunt, 2010). Otago students nevertheless, were keen to undertake research and identified key tasks and key foci that already occur in the everyday world of social work practice. Their definitions of social work research were congruent with those academics who argue for research aligned to social work values, principles and traditional aims (Dominelli, 2005; McDermott, 1996; Witkin, 2000), but some students were also quite pragmatic about the need to let the research question dictate the choice of methods, the aim of a project and whether the research should be empowerment oriented or not.

While students were enthused about undertaking research when training they understood the challenges to continuing once qualified. Often there is little continuity between gaining some good practice-based research skills while at a training institution and then using these to improve practice once working as a social worker. There are some useful examples where practitioners have continued to use the skills they gained once qualified. Fouché and Lunt (2010) describe how 43 practitioners in New Zealand were mentored to undertake and disseminate small-scale practice-based research projects. They use the term 'nested mentoring' to refer to the way in which practitioners might be mentored to do research by working in partnership with academic researchers. Nested mentoring emphasises collaboration, as well as a reciprocity in communication, multi-level relationships, and research that is dynamic and flexible, and enables a commitment to advance research in practice. Peer mentoring, in addition to any assistance offered by academic researchers, is crucial as a facilitator of practitioner research. 
In the UK, Sharland (2009, p. 58) noted that the 'cycle of separation between research and practice begins at qualifying stage'. Some concerns expressed including having too narrow a view of research as not being applicable to practice, and not encouraging research mindedness in social work graduates. It is important therefore in the context of what social work students from New Zealand have said that social work education establishments do ensure that enough specific and relevant social work research material is taught. This will enable social work graduates to apply their knowledge in specific ways to practices as a way of benefitting social work client groups. In the United States, for example, graduates of social work, in contrast to those from the UK and New Zealand, start work feeling competent and capable of doing research of benefit to the profession (Sharland, 2009). Perhaps lessons can be learned from their different training structures where research training is central rather than an add-on (Unrau \& Grinnell, 2005).

\section{Conclusion}

Constructions of social work research by students in training will influence the nature of the research they may undertake as practitioners and whether or not they view social work research as integral to their everyday practice. The students in this study believed in social work research as compatible with social work values, to be of use and importance in everyday social work and needing to be aimed at positive benefits for service users and communities. It is important that once qualified, practitioners are supported to use their knowledge and skills to enhance effectiveness in practice. By continuing to evaluate their everyday work they can support their desire to make a positive difference to the lives of service users.

\section{References}

Beddoe, L. (2010). Investing in the future: Social workers talk about research. British Journal of Social Work Advance Access, December 2010, 1-19.

Beresford, P., \& Croft, S. (2001). Service users' knowledges and the social construction of social work. Journal of Social Work, 1, 295-316.

Carpenter, J. (2000). Multidisciplinarity: Parameters and boundaries in social work research. ESRC Theorising Social Work Research Seminar 6. Retrieved 10 December 2010, from http:/ / www.scie.org.uk/publications/misc/ tswr/ seminar6/carpenter.asp

Dominelli, L. (2005). Social work research: Contested knowledge for practice. In R. Adams, L. Dominelli, \& M. Payne (Eds.), Social work futures. Crossing boundaries, transforming practice. Basingstoke: Palgrave Macmillan.

Fook, J. (2009). What does practice research mean and is it a relevant concept? Keynote Address, 1st Annual Nordic Husk Conference. Oslo College, Oslo, June.

Fouché, C., \& Lunt, N. (2010). Nested mentoring relationships: Reflections on a practice project for mentoring research capacity amongst social work practitioners. Journal of Social Work, 10, 391-406.

Humphries, B. (2008). Social work research for social justice. Basingstoke, Hampshire: Palgrave Macmillan.

Martinez-Brawley, E. (2001). Searching again and again. Inclusion, heterogeneity and social work research. British Journal of Social Work Research, 31, 271-85.

McDermott, F. (1996). Social work research: Debating the boundaries. Australian Social Work, 49, 5-10.

McLaughlin, H. (2007). Understanding social work research. London: SAGE.

Nash. M. (2010). Self-reflexive student research and its implications for social work education. Social Work Education, 30, 331-344.

Orme, J., \& Powell, J. (2007). Building research capacity in social work: Process and issues. British Journal of Social Work, 38, 988-1008.

Pease, B. (2010). Challenging the dominant paradigm: Social work research, social justice and social change. In I. Shaw, K. Briar-Lawson, J. Orme, \& R. Ruckdeschel (Eds.), The SAGE handbook of social work research. London: SAGE.

Phillips, C., \& Shaw, I. (2011) Editorial: Innovation and the practice of social work research. British Journal of Social Work, 41, 609-624.

Powell, J. \& Ramos, B. (2010). The practice of social work research. In I. Shaw, K. Briar-Lawson, J. Orme \& R. Ruckdeschel (Eds.), The SAGE handbook of social work research. London: SAGE.

Sharland, E. (2009). Strategic adviser for social work and social care research main report. Retrieved 1st September 2011, from http:/ / www.esrcsocietytoday.ac.uk/about-esrc/what-we-do/health.aspx 
Shaw, I. (2007). Is social work research distinctive? Social Work Education, 26, 659-69.

Shaw, I., Briar-Lawson, K., Orme, J., \& Ruckdeschel, R. (2010). (Eds.) The SAGE handbook of social work research. London: SAGE.

Shaw, I., \& Lunt, N. (2011). Navigating practitioner research. British Journal of Social Work, 41, 1548-1565.

Shaw, I., \& Norton, M. (2008). Kinds and quality of social work research. British Journal of Social Work, 38, 953-70. Smith, R. (2009). Doing social work research. Maidenhead: Open University Press.

Thomas, D. (2006). A general inductive approach for analysing qualitative evaluation data. American Journal of Evaluation, 27, 237-246.

Unrau, Y. \& Grinnell Jr, R. (2005). The impact of social work research courses on research self-efficacy for social work research students. Social Work Education, 24, 639-651.

Witkin, S. (2000). An integrative human rights approach to social research. In C. Truman, D. Mertens, \& B. Humphries (Eds.), Research and inequality. London: UCL Press. 